\title{
Species of Xorides (Xorides) (Hymenoptera: Ichneumonidae: Xoridinae) parasitizing wood-boring insects in the Palaearctic part of China
}

\author{
Mao-Ling Sheng \& Jun-Bao Wen
}

Sheng, M-L. \& Wen, J-B. 2008: Species of Xorides (Xorides) (Hymenoptera: Ichneumonidae: Xoridinae) parasitizing wood-boring insects in the Palaearctic part of China. - Entomol. Fennica 19: 86-93.

Thirteen species of Xorides (Xorides) parasitizing wood-boring insects in trunks and branches of trees are reported. Three of them, X. (Xorides) pissodius Sheng \& Wen sp. n. reared from Pissodes nitidus Roelofs (Curculionidae, Coleoptera) in Larix principis-rupprechtii Mayr (Pinaceae), X. (Xorides) tumidus Sheng \& Wen sp. n. reared from Cerambycidae in Quercus sp. (Fagaceae) and X. (Xorides) longicaudus Sheng \& Wen sp. n. are new to science. X. (Xorides) ater (Gravenhorst, 1829) is a new record for China. Some new host records are provided. A key to species of Xorides (Xorides) of the Palaearctic part of China is presented.

M.-L. Sheng, The Key Laboratory for Silviculture and Conservation of Ministry of Education, Beijing Forestry University, 100083, P. R. China; General Station of Forest Pest Management, State Forestry Administration, 58, Huanghe North Street, Shenyang 110034, P. R. China; E-mail: shengmaoling@163.com J.-B. Wen, The Key Laboratory for Silviculture and Conservation of Ministry of Education, Beijing Forestry University, 100083, P. R. China.

Received 29 November 2005, accepted 4 July 2007

\section{Introduction}

The subgenus Xorides Latreille 1809 belonging to the genus Xorides of the ichneumonid subfamily Xoridinae are parasitoids of woodborers and are distributed worldwide except for the Australian Region (Townes 1970, Yu \& Horstmann 1997). A key to subgenus of genus Xorides and their diagnostic characters were provided by Townes (1970). Nine species have previously been recorded from the Palaearctic part of China (Wang \& Gupta 1995, Liu \& Sheng 1998, Sheng et al. 2002). This study is based largely upon material reared from wood-boring insects by the authors and has resulted in the recognition of a total of thirteen species, three of which are new to sci- ence and one new record for China. The study has also resulted in several new host records.

\section{Methods}

Materials used were collected using the following methods.

Rearing parasitoids. Trunks and branches of naturally heavily infested trees were brought to the laboratory and maintained in a large nylon cage at room-temperature. Water was sprayed over the trunks and branches twice a week and emerged insects collected daily.

Rearing parasitoid larvae and pupae. Parasitoid larvae and cocoons were collected from 
galleries of wood-borer infested logs, and stored individually in glass tubes with a piece of filter paper dipped in distilled water for keeping moisture and plugged tightly with absorbent cotton wool.

Direct collection. Parasitoid adults were collected from infested tree trunks and branches, and in forest generally, using standard insect nets.

Loaned material. Additional material was borrowed from the Zoologische Staatssammlung München, Germany, the Department of Forest Protection, Forest Research Institute, Warsaw, Poland and the Osaka Museum of Natural History, Osaka, Japan.

Identifying host specimens. Hosts, investigated from 1988 to 1990 in Tuqian, Daxing' anling, Heilongjiang Province, were identified by Prof. Fu-Ji Pu, Institute of Zoology, Chinese Academy of Sciences, P. R. China. Others were identified by comparing with the specimens deposited in Insect Museum, General Station of Forest Pest Management, State Forestry Administration, Shenyang, P. R. China. Some hosts can only be identified to family by the head shell of the incomplete dead insect in the gallery nearby parasitoid larvae or cocoons.

Morphological terminology mostly follows Townes (1969). Wing vein nomenclature is based upon Ross (1936) and the terminology of Mason (1986).

All specimens of Ichneumonidae and hosts except those identified by Prof. Fu-Ji Pu preserved in Institute of Zoology, Chinese Academy of Sciences, P. R. China, are deposited in Insect Museum, General Station of Forest Pest Management, State Forestry Administration, P. R. China.

\section{Descriptions of new species of Xorides (Xorides) and records and host information of other species in Palaearctic China}

Subgenus Xorides Latreille, 1809

Xorides Latreille, 1809. Genera Crustaceorum et Insectorum secundum ordinem naturalem in familias disposita iconibus exemplisque plurimis explicata, 4:4. Type specimen: Ichneumon indicatorius Latreille.
Diagnosis. Fore wing with 1cu-a distal of $1 / \mathrm{M}$. 2rs-m to base of $2 \mathrm{~m}$-cu by more than its length. All trochanters without teeth.

\subsection{Xorides (Xorides) longicaudus Sheng \& Wen sp. n. (Fig. 1)}

Material examined. Holotype $\bigcirc$, Ganshan Park, $1,000 \mathrm{~m}, \mathrm{~N} 34^{\circ} 42^{\prime}, \mathrm{E} 111^{\circ} 06^{\prime}$, Shanxian County, Henan Province, 31.V.2000, Mei-Cai Wei. Type is deposited in Insect Museum, General Station of Forest Pest Management, State Forestry Administration, Shenyang, P. R. China.

Diagnosis. The new species is similar to $X$. (X.) furcatus Liu et Sheng, 1998 but can be distinguished from the latter by inner orbits black, postocellar line 1.3 times as long as ocular-ocellar line, wings without brown mark, first tergite of metasoma about 3.6 times longer than its apical width. $X$. $(X$.) furcatus with inner orbits white, postocellar line about as long as ocular-ocellar line, wings with brown marks, first tergite of metasoma about 2 times longer than its apical width.

Description. Holotype female: Body length about $18 \mathrm{~mm}$. Forewing length about $13 \mathrm{~mm}$. Face convex, about 0.5 times as long as wide, with dense transverse wrinkles and indistinct punctures. Clypeal suture distinct, middle section between clypeal foveas straight. Clypeus flat, its sub-base with a distinct transverse ridge. Labrum crescent, its apical margin with dense hairs. Subocular sulcus distinct. Malar space 0.7 times as long as basal width of mandible. Temple weakly swollen, with dense longitudinal wrinkles, front and hind portions with punctures. Vertex evenly convex, with dense punctures (Fig. 1a), hind portion with short transverse wrinkles. Postocellar line 1.3 times as long as ocularocellar line. Frons weakly convex, with dense punctures and a median longitudinal groove, upper portion with oblique transverse wrinkles. Occipital carina widely interrupted in the median dorsal area. Antenna filiform with 27 flagellomeres, flagellomeres 22 to 26 with peglike bristles. Lower portion of pronotum with short longitudinal wrinkles. Mesoscutum with dense punctures, hind portion with dense longitudinal wrinkles. Scuto-scutellar groove with a median longi- 

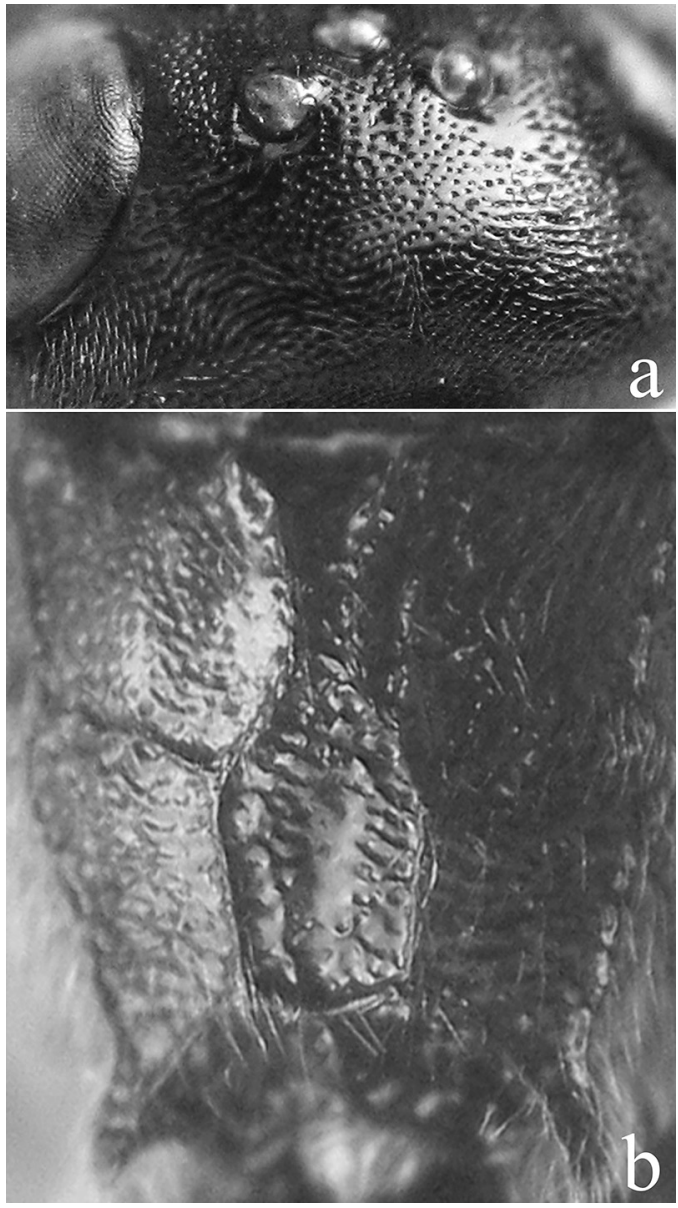

Fig. 1. X. (Xorides) longicaudus sp. n. - a. Vertex showing punctures. - b. Propodeum.

tudinal carina. Mesopleuron with dense and fine punctures. Speculum distinct. Metapleuron rough. Propodeum areolated completely (Fig. 1b). Basal area long, apical halves of its lateral carinae nearly parallel. Areola hexagonal. Propodeal apophysis strong. Propodeal spiracle narrow. Wing hyaline. Fore wing with $1 \mathrm{cu}-\mathrm{c}$ distal of 1/M; 3rs-m absent; 2rs-m wide and very short, 0.18 times as long as the distance between it to $2 \mathrm{~m}$-cu. Hind wing veins $1 / \mathrm{Cu}$ and cu-a about equal. First tergite of metasoma slightly rough, about 3.6 times longer than its apical width, lateral sides of apical portion with fine transverse wrinkles; median dorsal carinae reaching to hind margin of first tergite; dorsolateral carina very indistinct. Second tergite distinctly longer than its apical width, slightly rough, lateral side of basal portion with bowed out groove. Third tergite slightly longer than its apical width. Apical portion of eighth tergite elongate. Ovipositor sheath $19.5 \mathrm{~mm}$ long. Apical portion of lower valve of ovipositor with 8 ridges, basal 5 ridges very strong.

Black. Flagellomeres 9 to 13 and basal half of 14 , marks on outer sides of basal portions of front and middle tibiae, basal rings of hind tibiae, apical halves of tarsomere 1,2 to 4, and base of stigma white. Apical portion of palpi blackish. Clypeus, basal portions of mandibles and front sides of fore femora except base brown. Front sides of middle tibiae and inner sides of hind tibiae darkish brown. Front sides of fore tibiae, front and middle tarsomeres 1 to 4 grayish black.

Etymology. Specific name derived from the long and thick ovipositor sheath.

\subsection{Xorides (Xorides) pissodius Sheng \& Wen sp. n. (Fig. 2)}

Material examined. Holotype + , Liupanshan, 1900m, N35²4', E106 23', Ningxia, 12.VI. 2005 , reared from a cocoon collected from galleries of Pissodes nitidus Roelofs (Curculionidae), Mao-Ling Sheng. Type is deposited in Insect Museum, General Station of Forest Pest Management, State Forestry Administration, Shenyang, P. R. China.

Diagnosis. This new species is similar to $X$. (X.) brachylabis (Kriechbaumer 1889) and can be distinguished from the latter by frons with dense transverse wrinkles; inner orbits black; ovipositor sheath 1.4X longer than hind tibia. X. (Xorides) brachylabis (Kriechbaumer): frons with fine punctures; inner orbits yellowish white; ovipositor sheath 2.6X longer than hind tibia.

Description. Holotype female: Body length about $6.1 \mathrm{~mm}$. Forewing length about $4.5 \mathrm{~mm}$. Face about 0.44 times as long as wide, with dense short-transverse wrinkles and punctures; its lateral sides with transverse wrinkles; evenly convex, slightly protuberant centrally. Clypeal suture distinct, middle section between clypeal foveas straight. Basal margin of clypeus with very fine transverse lines; near its base with a distinct transverse ridge, under the ridge flat and nearly smooth; lateral side with very weak transverse 

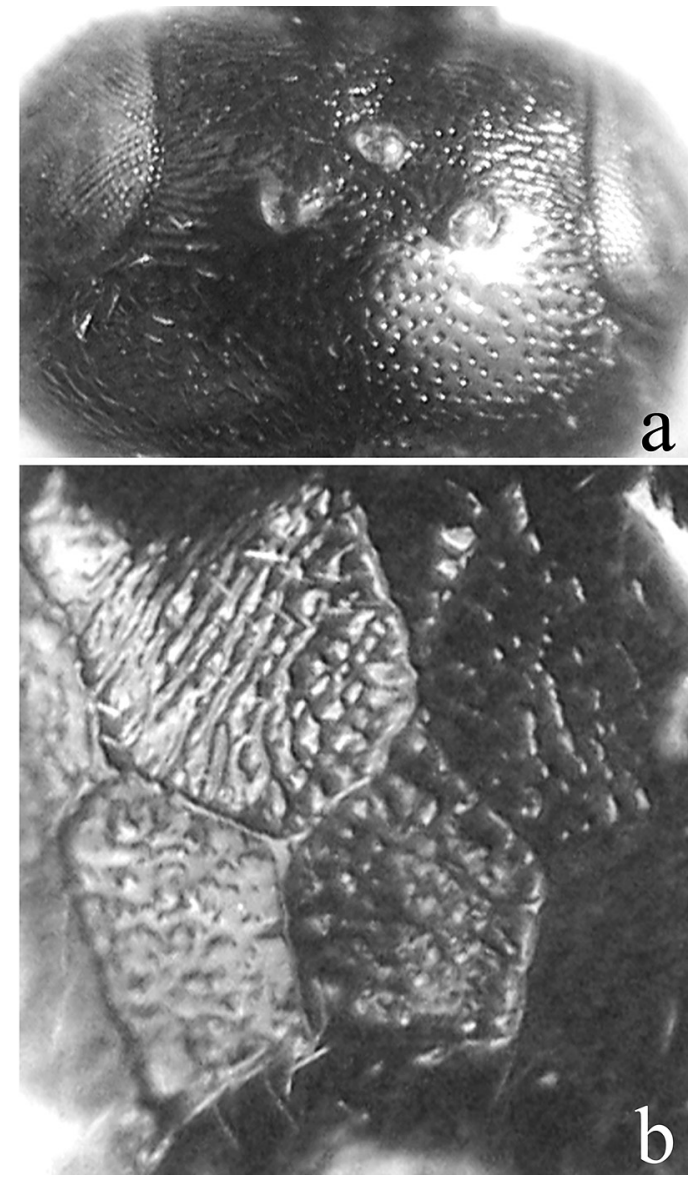

Fig. 2. X. (Xorides) pissodius sp. n. - a. Vertex showing punctures. $-b$. Propodeum.

lines. Subocular sulcus distinct. Malar space about as long as basal width of mandible. Temple weakly swollen, with dense oblique-longitudinal wrinkles, front portion with dense transverse wrinkles. Vertex evenly convex, with dense and even punctures (Fig. 2a). Posto-cellar line 1.4 times as long as ocular-ocellar line. Frons with dense transverse wrinkles and a median longitudinal groove. Antenna filiform with 20 flagellomeres; each of the flagellomeres longer than wide; with 5 peglike bristles on flagellomeres 18 to 20. Occipital carina complete. Front portion of pronotum with dense longitudinal wrinkles, hind portion with punctures. Mesoscutum rough, with unclear punctures, hind median portion with oblique wrinkles. Mesopleuron with fine and weak punctures. Metapleuron very rough, with dense and irregular reticulation. Wing brownish hyaline. Forewing vein 1cu-a distinctly distal of 1/M; 3rs-m absent; 2rs-m wide and short, 0.25 times as long as the distance between it and $2 \mathrm{~m}$ $\mathrm{cu}$. Hind wing veins $1 / \mathrm{Cu}$ and $\mathrm{cu}-\mathrm{a}$ equal. Propodeum (Fig. 2b) slightly rough, areolated completely; basal area triangular; areola pentagonal; apical area with indistinct longitudinal wrinkles; first lateral areas with oblique longitudinal wrinkles; other areas with very weak and irregular wrinkles. Propodeal apophysis strong. First tergite of metasoma 2.2 times longer than its apical width, with slight-rough leathery texture surface, median dorsal carinae indistinct, about reaching to half length of first tergite. Second and third tergites with dense and indistinct punctures; the former about as long as its apical width. Fourth and fifth tergites with very fine and short transverse lines. Ovipositor sheath about $3 \mathrm{~mm}$ long, 1.4X longer than hind tibia. Ovipositor thin, slightly downcurved, apical portion slightly depressed; apical portion of lower valve with 6 strong and inclivous ridges.

Body black except the following. Clypeus darkish brown. Base of mandible crimson. Longitudinal line on front sides of fore tibiae and lower sides of scape blurry yellowish white. Flagellomeres 9 to 12 white. Base of forewing 1cu-a and mark under stigma slightly darkish brown. Bases of tibiae darkish red. Fore and middle tarsi brownish.

Cocoon. Nearly columnar, about $9 \mathrm{~mm}$ long, median diameter about $1.7 \mathrm{~mm}$. Light brown.

Host. Cocoon of X. (Xorides) was found in galleries of Pissodes nitidus Roelofs (Curculionidae) in Larix principis-rupprechtii Mayr.

Etymology. Specific name derived from its host, Pissodes nitidus Roelofs.

\subsection{Xorides (Xorides) tumidus Sheng \& Wen sp. n. (Fig. 3)}

Material examined. Holotype + , Xinbin, N4131', E12459', Liaoning Province, 20.VI. 1998, reared from trunks of Quercus sp. with longhorns (Cerambycidae), Mao-Ling Sheng. Deposited in Insect Museum, General Station of Forest Pest Management, State Forestry Administration, Shenyang, P.R. China.

Diagnosis. This new species is similar to $X$. 


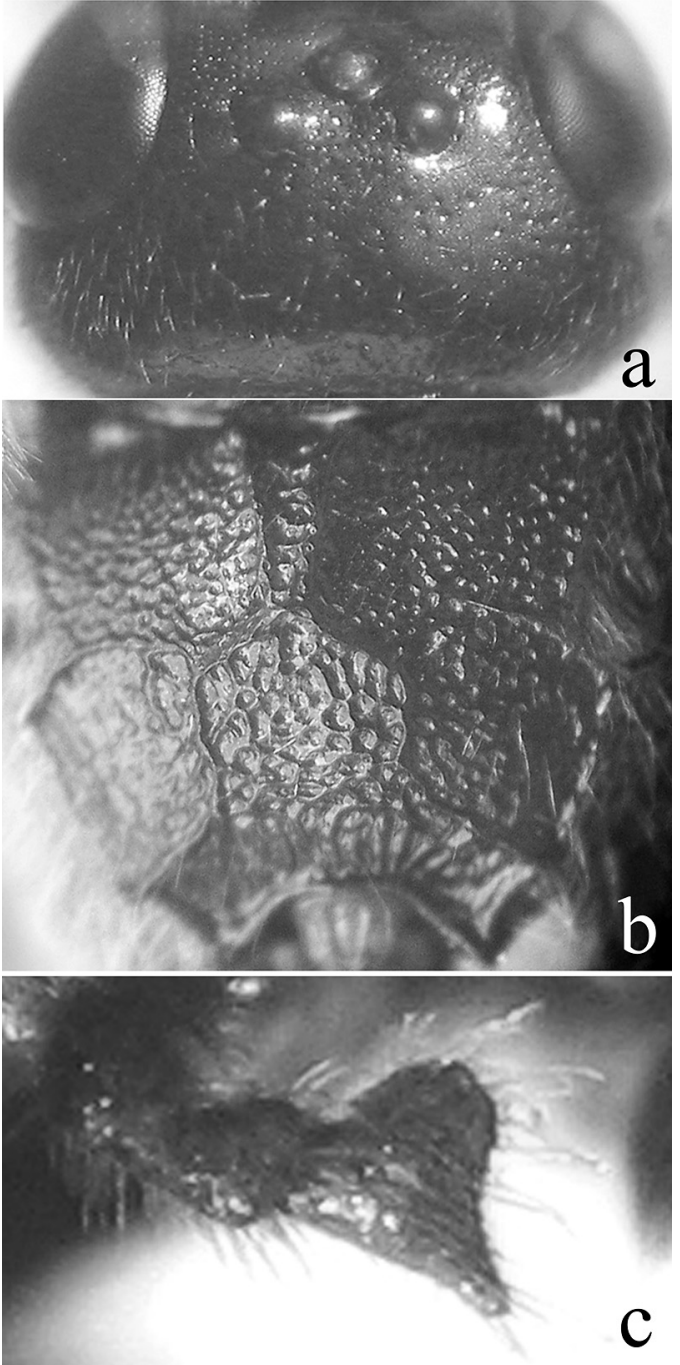

Fig. 3. X. (Xorides) tumidus sp. n. - a. Vertex showing punctures. - b. Propodeum. - c. Apical segment of labial palpus.

(Xorides) brachylabis Kriechbaumer and can be distinguished from the latter by the apical 3 segments of labial palpi short and very thick; median portion of apical segment strongly swollen dorsally subspherically, slightly depressed, apical portion very small and acuity; areola combined with apical area; orbits and tegulae black; legs mainly blackish brown to black. $X$. (Xorides) brachylabis has normal not swollen labial palpi; areola separated from apical area by apical transverse carina; inner orbits and tegulae yellowish white; legs mainly with light color.
Description. Holotype female: Body length about $14.5 \mathrm{~mm}$. Forewing length about $11.5 \mathrm{~mm}$. Face 0.6 times as long as wide, slightly convex, with dense punctures, lateral portion with short transverse wrinkles; lower portion with short longitudinal wrinkles. Clypeal suture distinct. Clypeus smooth, near its base with a distinct transverse ridge, under the ridge flat. Each of apical 3 segments of labial palpi short and with very thick apical portion; median portion of apical segment (Fig. 3c) strongly swollen dorsally and slightly depressed, apical portion very small and tapered. Subocular sulcus distinct. Cheek smooth, inner portion with fine and sparse punctures, outer portion with dense longitudinal wrinkles. Malar space 0.5 times as long as basal width of mandible. Lower portion of temple with weak longitudinal wrinkles, upper portion with very shallow and sparse punctures. Vertex evenly convex, with sparse punctures (Fig. 3a). Postocellar line 1.3 times as long as ocular-ocellar line. Frons with very shallow and even punctures. Antenna with 28 flagellomeres; peg-like bristles on flagellomeres 22 to 25 . Occipital carina complete. Pronotum smooth, front margin with dense longitudinal wrinkles, lateral side concave with dense and short transverse wrinkles, hind portion with punctures. Mesoscutum with dense punctures, hind median portion with short wrinkles. Mesopleuron smooth, with very fine and sparse punctures. Metapleuron rough, with very dense and irregular wrinkles. Wing brownish hyaline. Forewing vein $1 \mathrm{cu}-\mathrm{a}$ slightly distal of $1 / \mathrm{M}$; 3rs-m absent; 2rs-m short, 0.15 times as long as the distance between it and $2 \mathrm{~m}$-cu. Hind wing veins $1 / \mathrm{Cu}$ slightly longer than cu-a. Claws very small. Propodeum (Fig. 3b) with dense rough punctures. Basal area and outside of its longitudinal carinae with transverse wrinkles. Apical area with dense longitudinal wrinkles. Basal area long, nearly triangular, comparted from areola by basal transverse carina. Areola combined with apical area. Propodeal apophysis indistinct. First tergite of metasoma 2.0 times longer than its apical width, with very dense punctures; apical portion nearly flat, lateral portion with irregular wrinkles; median dorsal carinae present as a trace; spiracles convex. Other tergites transverse. Basal half of tergite 2 with dense punctures, lateral portions of apical half with irregular fine wrinkles. Tergite 3 
with very fine punctures, basal portion slightly rough. Tergites 4 to 7 with very weak and unclear transverse lines. Ovipositor sheath about $13 \mathrm{~mm}$ long. Ovipositor relatively slender, its apex bended down; apical portion of lower valve with 8 ridges, basal 4 ridges inclivous and very strong.

Body black except the following portions. Flagellomeres 11 to 14 white. Front femora and tibiae blackish brown. Front tarsus, middle tibiae and tarsus brownish black. Bases of femora darkish red.

Hosts. Reared from Cerambycidae in trunk of Quercus sp. (Fagaceae).

Etymology. This species name is based on the very swollen labial palpi.

\subsection{Xorides (Xorides) aculeatus}

Liu \& Sheng, 1998

Material examined. $1 \hat{\jmath}$, China: Xinbin, Liaoning Province, 29.V.1994, Mao-Ling Sheng.

Hosts. Reared from Cerambycidae under the bark of Quercus sp.

\subsection{Xorides (Xorides) ater (Gravenhorst, 1829)}

New record for China.

Material examined. 1q, Tuqian, Daxing' anling, Heilongjiang Province, 24.VII.1989, Mao-Ling Sheng.

Host. Reared from Tetropium sp. (Cerambycidae) under the bark of Larix gmelini (Rupr.) Rupr.

\subsection{Xorides (Xorides) brachylabis (Kriechbaumer, 1889)}

Material examined. 1 , , Tuqian, Daxing'anling, Heilongjiang Province, 16.VII.1988, Mao-Ling Sheng; 2 우, Tuqian, Daxing'anling, Heilongjiang Province, 24.VII.1989, Mao-Ling Sheng.

Host. Reared from Cerambycidae in trunk of Larix gmelini (Rupr.) Rupr.

\subsection{Xorides (Xorides) erigentis Wang \& Gupta, 1995}

Material examined. 1 온, Tuqian, Daxing'anling, Heilongjiang Province, 16.VII.1988, Mao-Ling Sheng.

Host. Reared from Cerambycidae in trunk of Larix gmelini (Rupr.) Rupr.

\subsection{Xorides (Xorides) furcatus \\ Liu \& Sheng, 1998}

Material examined. 19 , Mianchi, Henan Province, May, 1981, Zhen-Ya Shi.

Host. Unknown.

\subsection{Xorides (Xorides) hirtus \\ Liu \& Sheng, 1998}

Material examined. $2 \hat{\jmath}$, Xinbin, Liaoning Province, 28.V.1994, Mao-Ling Sheng; 1ठð, Xinbin, Liaoning Province, 29.V.1994, Mao-Ling Sheng; 1ठ̃, Lushuihe, Jilin Province, 25.VII.1994, ShuPing Sun.

Hosts. Cerambycid in trunk of Quercus sp.

\subsection{Xorides (Xorides) irrigator (Fabricius, 1793)}

Material examined. $39 q$, Tuqian, Daxing' anling, Heilongjiang Province, 5.VI.1989, MaoLing Sheng; 17우, 3ภㅅ, Tuqian, Daxing' anling, Heilongjiang Province, 14.-28.VII.1989, Mao-Ling Sheng.

Host. Reared from Tetropium castaneus (L.) and Tetropium gabrieli in branches and trunk of Larix gmelini (Rupr.) Rupr.

\subsection{Xorides (Xorides) praecatorius} (Fabricius, 1793)

Material examined. 1ڤึ, Xiaoxing'anling, Heilongjiang Province, VII.1995, Shu-Ping Sun. Host. Unknown. 


\subsection{Xorides (Xorides) sapporensis (Uchida, 1928)}

Material examined. 1§̄, Shenyang, Liaoning Province, 30.VII.1990, Mao-Ling Sheng; 2 우, $4 \lesssim \widehat{\jmath}$, Shenyang, Liaoning Province, 19.-20.V. 1991, Mao-Ling Sheng; 1ㅇ, 2ðð, Shenyang, Liaoning Province, 4.VI.1991, Mao-Ling Sheng; 1ㅇ, Shenyang, Liaoning Province, 2.VII.1991, Mao-Ling Sheng; 19 , Xinbin, Liaoning Province, 5.VIII.1997, Mao-Ling Sheng; 19, Shenyang, Liaoning Province, 22.V.1999, Mao-Ling Sheng; 1 , Shenyang, Liaoning Province, 31.V. 2000, Mao-Ling Sheng; $3 ㅇ++, 3 \widehat{\jmath} \widehat{\jmath}$, Kuandian, 400 m.a.s.1., Liaoning Province, 2.VI.2001, MaoLing Sheng; 1 ,, $3 \hat{\jmath} \widehat{\jmath}$, Caihe, Heilongjiang Province, 25.V.2002, De-Jun Hao; 19, Harbin, Heilongjiang Province, 7.VI.2002, De-Jun Hao; $1+6 \hat{\jmath}$, Harbin, Heilongjiang Province, 13.VIII.2002, De-Jun Hao; 2 우, $2 \hat{\jmath}$ ऽ, Harbin, Heilongjiang Province, 25.V.2002, De-Jun Hao; $1+$, Jiagedaqi, Heilongjiang Province, 30.VIII. 2002, De-Jun Hao; 1 , , Shenyang, Liaoning Province, 30.VII.2003, Mao-Ling Sheng; 1ㅇ, Shenyang, Liaoning Province, 15.V.2004, MaoLing Sheng.

Hosts. Reared from larvae of Agrilus marcopoli Obenberger (Coleoptera: Buprestidae) in branches of Fraxinus sp. and other wood-boring Cerambycidae in Quercus sp. and Prunus spp.

\subsection{Xorides (Xorides) sepulchralis (Holmgren, 1860)}

Material examined. 1 , , Huinan, Jilin Province, 12.VII.1991; 2 우, 1 ऽ, Lushuihe, Jilin Province, 25.VII.1991; 1 ㅇ, 17ふึ, Xinbin, Liaoning Province, 28.-29.V.1994, Mao-Ling Sheng; 1ð, Daxingguo, Jilin Province, 9.VII.1994, MaoLing Sheng; 19, Longyuwan Natural Reserve, 1050m.a.s.1., Luanchuan, Henan Province, 22.V.1999, Mao-Ling Sheng; 10 , Baihe, Jilin Province, 8.VI.2002, De-Jun Hao; 1 , , Tonghua, Jilin Province, 8.VI.2002, De-Jun Hao.

Hosts. Reared from Massicus raddei Blessig (Coleoptera: Cerambycidae).in branch and trunk of Quercus liaotungensis Koidz.

\section{Key to the species of Xorides (Xorides) from the Palaearctic part of China}

Females

1. Thorax and/or metasoma with large light flecks.

2

Thorax and metasoma black, without light flecks.

2. Median dorsal carinae of first tergite of metasoma reaching to hind margin of first tergite. Body at least metasoma with yellow or white marks.

3

Median dorsal carinae of first tergite of metasoma not reaching to hind margin of first tergite. Thorax or metasoma with red or reddish brown marks.

4

3. Second tergite of metasoma with fine reticulate surface. Thorax and metasoma with many yellow and white marks.

$X .(X$.$) praecatorius (Fabricius)$ Second tergite of metasoma with irregular longitudinal wrinkles. Thorax black. Tergites 4 to 6 posterolaterally with big white marks.

$X .(X$.$) sapporensis (Uchida)$

4. Frons with dense transverse wrinkles. Antenna with white ring. Fore wing with dark fleck under stigma. Tergites 1 and 2 red.

$X$. (X.) irrigator (Fabricius) Frons with fine punctures. Antenna without white ring. Fore wing without fleck. Metasoma entirely black.

$X .(X$.$) ater (Gravenhorst)$

5. Occipital carina dorso-medially interrupted. 6 Occipital carina complete.

6. Basal area of propodeum separated from areola by basal transverse carina. First tergite 3.6 times longer than its apical width. (Male unknown)

$X$. (X.) longicaudus, sp.nov. Basal area combined with areola. First tergite at most 2.5 times longer than its apical width. 7

7. Ovipositor sheath $0.6-0.7 \mathrm{X}$ as long as fore wing. Areola confluent with basal area. Fore wing with darkish brown flecks.

$X$. (X.) furcatus Liu et Sheng Ovipositor sheath at least as long as fore wing. Areola comparted from basal area by basal transverse carina. Fore wing without fleck. 8

8. Malar space as long as basal width of mandi- 
ble. First tergite 2.4 times longer than its apical width. Frons orbits entirely black.

$X$. $(X$.) erigentis Wang \& Gupta Malar space about $0.6 \mathrm{X}$ as long as basal width of mandible. First tergite 2.0 times longer than its apical width. Frontal orbits white.

$$
X \text {. }(X \text {.) sepulchralis (Holmgren) }
$$

9. Each of apical 3 segments of labial palpi short and with very thick apical portion; median portion of apical segment (Fig. 3c) strongly swollen dorsally and slightly depressed, apical portion very small and tapered. Basal area of propodeum separated from areola by carina. Areola combined with apical area. (Male unknown). $\quad X .(X$.$) tumidus, sp. nov.$ Labial palpi normal, not tumid. Basal area combined with areola. Areola separated from apical area by carina.

10

10. First lateral areas of propodeum with oblique longitudinal wrinkles (Fig. 2b). Inner orbits black. (Male unknown).

$X .(X$.$) pissodius, n.sp.$ First lateral areas of propodeum with punctures. Inner orbits white.

$$
\text { X. (X.) brachylabis (Kriechbaumer) }
$$

Males

1. Stigma short and wide, about $3 \mathrm{X}$ as long as wide.

Stigma long and narrow, at least $4 \mathrm{X}$ longer than its width.

2. Flagellomeres with erective and long hairs, the hairs longer than width of flagellomeres. 3 Flagellomeres with short to moderately long hairs, the hairs not more than $0.9 \mathrm{X}$ as long as width of flagellomeres.

3. Basal area of propodeum quadrangular, $0.6 \mathrm{X}$ as long as areola. Fore and middle tibiae brown to light brown. orbits white. (Female unknown).

$X .(X$.$) hirtus Liu et Sheng$ Basal area of propodeum triangular, $0.9 \mathrm{X}$ as long as areola. Fore and middle tibiae brownish black. $\quad X .(X$.$) sapporensis (Uchida)$

4. Facial orbits white. Metasoma with tergites 1 and 2 reddish. $\quad X$. (X.) irrigator Fabricius Facial orbits black. Metasoma black. $X$. $(X$.) praecatorius Fabricius
5. Median dorsal carina of first tergite of metasom complete, reaching to hind margin of first tergite. Occipital carina interrupted medio-dorsally.

X.(X.) sepulchralis (Holmgren)

Median dorsal carina of first tergite of metasom at most reaching to $2 / 3$ of first tergite. Occipital carina complete.

6. Face entirely black. (Female unknown).

$X .(X$.) aculeatus Liu et Sheng

Face partly or entirely white.

\section{7}

7. Face entirely white.

$$
\text { X. (X.) brachylabis (Kriechbaumer) }
$$

Face partly with whitish fleck.

$$
X .(X .) \text { ater Gravenhorst }
$$

Acknowledgements. We are deeply grateful to Dr. Donald Quicke, Division of Biology, Imperial College London, UK, for reviewing this manuscript. We also thank Dr. Klaus Schönitzer, Zoologische Staatssammlung München, Germany, Dr. Jacek Hilszczanski, Department of Forest Protection, Forest Research Institute, Warsaw, Poland, and Dr. Rikio Matsumoto, Osaka Museum of Natural History, Osaka, Japan, for their kindness in offering valuable material and lending specimens. Financial support from the National Natural Science Foundation of China (NSFC, No. 30471397) is thankfully acknowledged.

\section{References}

Liu, T. \& Sheng, M.-L. 1998: Studies on the genus Xorides (Xorides) from Northeast China. — Entomol. Sinica 5(1): 35-41.

Mason, W. R. M. 1986: Standard drawing conventions and definitions for venational and other features of wings of Hymenoptera. - Proc. Entomol. Soc. Washington 88: $1-7$.

Ross, H. H. 1936: The ancestry and wing venation of the Hymenoptera. — Ann. Entomol. Soc. Amer. 29: 99111.

Sheng, M.-L., Kou, M., Cui, Y.-S., Sun, S.-P. \& Su, W. 2002: A list of ichneumonids parasitizing tree bores in North China. - J. Gansu Forest. Sci. Tech. 27(3): 1-5.

Townes, H. K. 1970 (1969): The genera of Ichneumonidae, Part 1. - Mem. Amer. Entomol. Inst. 11: 1300.

Wang, S. F. \& Gupta, V. K. 1995: Studies on the xoridine ichneumonids of China (Hymenoptera: Ichneumonidae: Xoridinae). - Oriental Insects 29: 1-21.

Yu, D. S. \& Horstmann, K. 1997: A catalogue of world Ichneumonidae (Hymenoptera). - Mem. Amer. Entomol. Inst. 58: 1-1558. 